\title{
ANÁLISE SISTÊMICA DA LEGISLAÇÃO AMBIENTAL E DAS POLÍTICAS PÚBLICAS CONTRA O DESMATAMENTO NO HAITI
}

Systemic Analysis of Environmental Legislation and Public Policies against Deforestation in Haiti

Analyse systémique de la Législation environnementale et des Politiques publiques contre la déforestation en Haïti

\section{Jhon-Kelly Monacé ${ }^{* 1}$, Mônica Aparecida da Rocha Silva ${ }^{2}$, Waldecy Rodrigues ${ }^{3}$}

${ }^{1}$ Doutorando em Desenvolvimento Regional, Universidade Federal do Tocantins, Palmas, Brasil.

${ }^{2}$ Professora, Programa de Pós-Graduação em Desenvolvimento Regional, Universidade Federal do Tocantins, Palmas, Brasil.

${ }^{3}$ Professor, Programa de Pós-Graduação em Desenvolvimento Regional, Universidade Federal do Tocantins, Palmas, Brasil.

*Correspondência: Programa de Pós-Graduação em Desenvolvimento Regional (PPGDR), Universidade Federal do Tocantins, Av. NS 15, 109 Norte, Palmas, Tocantins, Brasil. CEP:77.010-090. e-mail jhon-

kelly.monace@mail.uft.edu.br.

\section{Artigo recebido em 31/03/2020 aprovado em 30/10/2020 publicado em 30/12/2020.}

\section{RESUMO}

Este artigo tem o objetivo de apresentar um diagnóstico parcial das políticas públicas haitianas contra o desmatamento. À luz da análise sistêmica, argumenta-se que a ausência de políticas públicas relacionadas ao setor energético e a falta de políticas públicas ambientais eficientes, criam condições nas quais a população é forçada, por livre e espontânea vontade, a usar os recursos florestais para satisfazer suas necessidades energéticas.

Palavras-chave: Análise Sistêmica; meio ambiente; Haiti.

\section{ABSTRACT}

This article aims to present a partial diagnosis of Haitian public policies against deforestation. In the light of a systemic analysis, we argue that the absence of Public Policies related to the sector of energy and the lack of efficient environmental public policies create conditions in which the population has no other choice, except using the forest resources to satisfy their energy needs.

Keywords: Systemic analysis; environment; Haiti.

RÉSUMÉ

Cet article vise à présenter un diagnostic partiel des Politiques publiques haïtiennes contre la déforestation. À la lumière de l'analyse systémique, cet article soutient que l'absence de politiques publiques liées au secteur de l'énergie et l'absence de Politiques publiques environnementales efficaces créent des conditions qui obligent la population à épuiser les ressources forestières pour répondre à ses besoins énergétiques.

Mots-clés: Analyse systémique; environnement; Haïti. 


\section{INTRODUÇÃO}

A República do Haiti, com suas ilhas adjacentes ( $L a$ Gonâve, Ile de la Tortue, Les Cayemites, Grosse Caye, Navase e as outras ilhas do mar territorial) tem uma área de $27.750 \mathrm{~km}^{2}$ e ocupa o terço ocidental da ilha do Haiti ou ilha de Hispaniola, posicionada no arquipélago das Grandes Antilhas. A República do Haiti compartilha a mesma ilha com a República Dominicana. O país é dividido administrativamente em dez departamentos geográficos: Norte, Nordeste, Noroeste, l'Artibonite, Centro, Oeste, Sul, a Grand'Anse, les Nippes e Sudoeste. De acordo com o Institut Haïtien de Statistiques et d'Informatique - Instituto Haitiano de Estatísticas e de Informática - IHSI, a população haitiana é estimada em mais de 11 milhões de habitantes em 2018 (INSTITUT HAÏTIEN DE STATISTIQUES ET D'INFORMATIQUE, 2015).

Em 01 de janeiro de 1804, o Haiti proclamou sua independência após a revolução dos escravos da colônia francesa de Saint Domingue e tornou-se o primeiro estado de raça negra da América e, mais tarde, a primeira República negra do mundo. É também o segundo estado livre e independente da América. Atualmente, o Haiti é mais conhecido pela sua situação de pobreza e miséria, em que é o único país da América que está dentre a lista dos Países Menos Avançados PMA.

O Haiti está enfrentando crises sistêmicas que vinculadas aos níveis político, socioeconômico e ambiental. Essas crises sistêmicas têm consequências na deterioração do ambiente natural e o espaço de convivência. Além disso, a posição geográfica do país, lhe expõe aos riscos naturais, contribuindo com o agravamento da crise ambiental como: terremotos, tempestades, furacões dentre outros.
O desmatamento é um problema ambiental que desafia tanto o Estado haitiano quanto sua população. A redução na área de florestas naturais haitianas é de origem diversa. De acordo com o IHSI (2001), é evidente que as necessidades do setor de energia deterioram mais ainda as florestas. A situação atual da degradação ambientxxal pode ser encontrada em vários níveis, envolvendo assim, fatores demográficos, econômicos, políticos e culturais. No aspecto demográfico, há a observação de uma economia fraca acompanhada por uma alta taxa de crescimento populacional que questiona o sistema societal e ambiental (DORVILIER, 2012).

De acordo com o Comité Interministériel de Développement Territorial (2010), a atual cobertura florestal primária do Haiti de todos os tipos combinados - manguezais, florestas secas, reservas florestais, parques naturais -é inferior a $02 \%$, enquanto a cobertura florestal da República Dominicana, outro país da ilha do Haiti, é avaliada a 47\%. O desmatamento, combinado com a vulnerabilidade do Haiti às tempestades e ciclones, exacerba a deterioração ambiental do país e afeta a produtividade de alimentos. Entre 1991 e 2002, a produção alimentar no Haiti diminui de $30 \%$ (COMITÉ INTERMINISTÉRIEL DE DÉVELOPPEMENT TERRITORIAL, 2010). Consequentemente, houve um aumento da pobreza rural e levou ao deslocamento da população camponesa para as grandes cidades, particularmente para Porto Príncipe, a capital. Em 1950, Haiti tinha uma população de 3.097 .920 composta de uma população urbana de 377.355 que representa $12 \%$ contra 2.719 .865 em zona rural. Em 2003, a população aumentou para 8.373.750, com uma população urbana de 3.418 .508 , quer dizer, $41 \%$ (PIERRE, 2014). A população foi estimada em 10.911.819 em 2015, com 5.667.686 residindo em 
regiões urbanas, ou seja, 52\% (IHSI, 2015). Sendo assim, o ciclo de pobreza alimenta o ciclo da degradação ambiental e se retroalimentam em um círculo vicioso, tornando a situação da "vulnerabilidade socioambiental" do Haiti, um terreno propício para o maior desastre já ocorrido nos últimos tempos (FREITAS et al, 2012).

Em resposta a esse problema ambiental, o estado está tentando retificar a situação por meio da elaboração de várias leis e vários projetos que nunca se atualizam ou se adaptam para resolver o problema. As leis são, portanto, teorias prontas que não são suficientemente eficientes na sociedade. Em suma, apesar da existência de leis, o estado não conseguiu elaborar e aplicar políticas públicas eficientes como resposta (output) que possa atender às necessidades energéticas (input) da população de modo a reduzir o desmatamento. A ineficiência das políticas públicas do Estado se combina com a intensificação das atividades socioeconômicas e, aliada às práticas inadequadas de manejo dos recursos florestais, provocam a degradação das florestas, resultando assim, em perda de biodiversidade e alterações no ciclo hidrológico, colaborando com as mudanças do clima (FREITAS et $a l, 2012)$.

Este artigo tem o objetivo de apresentar um diagnóstico parcial das políticas públicas haitianas contra o desmatamento. À luz da análise sistêmica, argumenta-se que a ausência de políticas públicas relacionadas ao setor energético e a falta de políticas públicas ambientais eficientes criam condições nas quais a população é forçada por livre e espontânea vontade a usar os recursos florestais para satisfazer suas necessidades energéticas.

\section{MATERIAIS E MÉTODOS}

O "meio ambiente", segundo o Ministère de l'Environnement - MDE - (2005) do Haiti, é o conjunto de elementos naturais e artificiais, bem como fatores econômicos, sociais e culturais que afetam os seres vivos e que estes podem o modificar. Os seres vivos se referem tanto aos humanos quanto aos animais e plantas. De outro modo, o meio ambiente é sistêmico no sentido de que todos os elementos vivos (biológicos) ou não vivos, mantêm vínculos com outros elementos em um ecossistema definido.

A partir da definição de MDE, pode-se ampliar a compreensão do aspecto sistêmico do ambiente para situar o homem em um meio ambiente econômico, político, social, cultural, físico e químico, mas acima de tudo, em que todos os elementos estão em interação permanente. $\mathrm{O}$ homem é um elemento deste conjunto em constante interação com os outros elementos do ecossistema.

O meio ambiente pode ser apresentado como um novo tema interdisciplinar em que há pesquisadores que focam seus estudos na relação entre homem e natureza. De maneira muito semelhante, o artigo 253 da Constituição da República do Haiti de 1987 afirma que o meio ambiente é a estrutura natural da vida da população. Quer dizer, o Estado tem a obrigação de tomar decisões políticas que possam harmonizar as relações entre a população e esse espaço natural de vida. Pesquisas mostram que o Estado haitiano não consegue manter ou garantir totalmente a harmonização entre o homem e o meio ambiente, em que uma das consequências é o desmatamento excessivo das florestas haitianas. $\mathrm{O}$ debate sobre $\mathrm{o}$ desmatamento não pode ser feito isoladamente. Assim, esta pesquisa tem como base a análise sistêmica para analisar o desmatamento no Haiti.

A análise sistêmica nas ciências sociais está relacionada principalmente aos estudos de políticas 
públicas como produto do sistema político que está mudando e buscando estabilidade. $\mathrm{O}$ equilíbrio entre a estabilidade e a mudança desse sistema se constitui em processos que se tornam um dos elementos mais importantes da "vida política", quer dizer, o conjunto complexo de processos por meio dos quais certas espécies de demandas (inputs) são convertidas em respostas (outputs) que podem ser chamadas de políticas autoritárias, decisões e ações concretizadas. Trata-se de um sistema de comportamento inserido em um contexto que influencia o próprio sistema político (EASTON, 1970). Em um esquema dinâmico, essas atividades são resumidas em torno de três variáveischave: inputs (entrada), Outputs (saída) e feedback (opinião) (PERCHERON, 1971). Sendo assim, David Easton (1970) ao analisar o sistema político, apresenta o sistema de elaboração de "output" (produtos manufaturados) a partir de "input" (matérias-primas). As matérias-primas são as exigências ou demandas dos membros do sistema político. Os produtos são as decisões e ações políticas (DYE, 2009; POLIN, 1971).

No modelo de análise proposto e desenvolvido por Easton (1970), as decisões são transformadas em políticas públicas, que são apenas as ações do governo ou dos líderes que se propõem a atingir os objetivos de interesse público, abordando-os eficientemente (AGUILAR, 2010). As decisões e ações do governo que visam responder às solicitações relacionadas constituem as políticas públicas. São a eficiência e a eficácia, para alcançar objetivos de interesse público, que falta na parte do estado haitiano. Com a teoria sistêmica, o artigo está caminhando para a demonstração de tal ineficiência do estado do Haiti frente ao desmatamento.

Este artigo é baseado ainda em uma metodologia que considera a análise de conteúdo dos documentos secundários de autores particulares e de leis sobre o desmatamento publicadas no " $L e$ Moniteur" o Diário oficial da República do Haiti. Esta apresentação permite encontrar fatos que mostram a ineficiência ou a falta de políticas públicas do estado frente ao desmatamento.

\section{AS LEIS AMBIENTAIS E AS DECISÕES DO ESTADO DO HAITI: A CRONOLOGIA DOS FATOS (1804 - 2006)}

Os grandes momentos da história do território haitiano não começaram com a independência em 1804. A primeira parte da história da ilha começa com os nativos. Este é um período que não é suficientemente dominado por falta de fontes escritas, mas esta história que durou alguns milênios, estava perto do seu fim com o desembarque dos europeus em 05 de dezembro de 1492. A partir deste ano, a ilha tornou-se a primeira colônia espanhola da América.

Antes da invasão dos europeus espanhóis em 1492, os primeiros habitantes da ilha do Haiti desfrutavam um ambiente praticamente saudável com uma cobertura florestal primária e com pouca intervenção dos seres humanos. Os próprios espanhóis deixaram testemunhos sobre o que observaram na natureza desta ilha (MADIOU, 1981). No entanto, esses mesmos espanhóis são também os primeiros a perturbar, pela primeira vez, a relação harmoniosa que existia entre o homem e a natureza na ilha do Haiti. Primeiro, concentraram-se na extração de metais preciosos reduzindo a primeira população da ilha à escravidão. Além disso, introduziram espécies de animais herbívoros ou vegetarianos (o cavalo, por exemplo) que gradualmente mudaram a flora da ilha (MADIOU, 1981; D’ANS, 1987).

Em 31 de outubro de 1627, marca oficialmente o início da colonização francesa da América, com a lei promulgando a associação dos Seigneurs des îles de 
l'Amérique (Senhores das Ilhas da América). Neste ato, a missão de habitar e povoar as ilhas de São Cristóvão, Barbados e outras ilhas do Caribe foi confiada aos Senhores Enambuc e Rossey (MOREAU DE SAINT MÉRY, 1784). Quanto à colonização francesa da ilha do Haiti, iniciou-se em 1630 com o estabelecimento de aventureiros franceses na Ile de la Tortue a noroeste de Saint Domingue. Após décadas de exploração e extermínio da população indígena, os confrontos armados entre espanhóis e franceses forçaram a Espanha a ceder o terço da ilha à França, após o Tratado de Ryswick em 1697 (MADIOU, 1981; MOREAU DE SAINT MÉRY, 1784; 1875).

Com o Tratado de Ryswick em 1697, os franceses instalaram-se gradualmente na parte ocidental da ilha para o estabelecimento de uma colônia de exploração com grandes plantações. Essas plantações exigiam muito espaço. Como resultado, os franceses atacaram a floresta primária para criar áreas suficientes para a agricultura. Além disso, o habitat humano atacou a floresta, já que na época, o principal material de construção era a madeira. Havia também uma exploração da floresta para transformar a madeira e exportá-las para a França (D’ANS, 1987; MADIOU, 1981). Com o tempo, esse comércio madeireiro foi estabelecido e mesmo após a Independência, continuava a perturbar a floresta primária.

Após a proclamação da independência do Haiti, as ações dos governos frente aos problemas ambientais foram expressas, principalmente por sua legislação. De 1860 a 2006, mais de 200 leis ou decretos ambientais foram elaborados pelos governos do Haiti (CADET, 2006). Um número significativo de textos ambientais diz respeito às áreas seguintes: planejamento urbano, agricultura e gerenciamento dos recursos naturais. Um texto sobre a legislação haitiana entre 1804 e 2000, publicado pelo Ministère de la
Justice et Sécurité Publique (MJSP), também foi apresentado em 2002, com uma lista de 140 textos sobre o meio ambiente, incluindo leis stricto sensu, decretos e Ordens (CADET, 2006). A questão do desmatamento foi identificada nas leis, decretos e ordens como um dos principais problemas do meio ambiente haitiano. As leis sobre árvores e florestas continuam sendo as mais abundantes em lei ambiental nacional (VICTOR, 1995). A maioria das publicações sobre a questão se estende entre 1864 e 2006.

A partir do período nacional, o Estado parecia estar articulando sua posição contra o desmatamento pela primeira vez no Código Rural que foi publicado em 1864, sessenta anos após a proclamação da Independência (VICTOR, 1995). Esta lei abordou o problema de maneira geral e expressou a ideia de proteger todas as espécies de plantas ameaçadas pelo desmatamento. O Código Rural proibia qualquer corte de lenha ou desmatamento não autorizado por um proprietário, ou pela administração de domínios do Estado. Tal ato deveria levar à prisão imediata do infrator pelo Chefe da Seção Rural, que o encaminhava ao juiz do município, com um relatório do fato. No Artigo 14, aborda-se o problema, afirmando que:

É proibido cortar lenha na crista das montanhas, a uma distância de cem passos da queda, na origem e ao redor das nascentes, ou nas margens dos rios; os proprietários das terras regadas por nascentes ou rios terão de plantar em torno dessas nascentes e nas margens dos rios, bambus e outras árvores que conterão a terra e manterão o ar fresco, sob a pena de uma multa de cem gourdes (RÉPUBLIQUE D’HAÏTI, 1864) (tradução nossa).

Desde esta lei, outras decisões do poder executivo tentaram regulamentar a questão do corte de árvores. Algumas continuam a abordar a questão em 
sua generalidade, enquanto outras estão especificamente interessadas em certas espécies de plantas.

Em 29 de fevereiro de 1904, o Presidente Nord Alexis promulgou uma lei para aumentar os impostos sobre a lenha de guaiac (Guaiacum officinale) que era considerada um dos produtos de exportação mais valorizados. Esta lei visava restringir a exploração da lenha de guaiac que era exportada principalmente para os Estados Unidos. No entanto, a aplicação da lei foi dificultada em 1915, uma vez que marca o início da ocupação do Haiti pelos Estados Unidos.

Figura 1. Cronograma da legislação haitiana contra o desmatamento.

\begin{tabular}{|c|c|}
\hline PÉRIODO DE PUBLICAÇÃO DAS LEIS & QUANTIA/PÉRIODO * \\
\hline (1860-1899) Início da legislação & 1 \\
\hline (1900-1909) Véspera da ocupação americana & 1 \\
\hline (1910-1934) Ocupação americana & 1 \\
\hline (1934-1939) Fim da ocupação & 4 \\
\hline (1940-1949) O problema sem solução & 3 \\
\hline (1950-1955) Véspera da ditadura dos Duvalier & 1 \\
\hline (1957-1969) A ditadura do Papa Doc & 3 \\
\hline (1970-1986) A ditadura do Baby Doc & 3 \\
\hline (1987-2006) A éra da democracia & 4 \\
\hline
\end{tabular}

Fonte: Elaboração própria (2020) com base no Le Moniteur Diário oficial do Haiti.

O problema do desmatamento se acelerava durante a ocupação estadosunidense do Haiti entre 1915 e 1934. Antes da ocupação, os camponeses ocupavam e exploravam áreas do Estado para estabelecer agricultura familiar de subsistência e venda de commodities, por exemplo, o café, que era vendido ao mercado internacional. Essa forma de agricultura permitiu que os camponeses, que compunham mais da metade da população, mobilizassem os recursos necessários para sua subsistência, sem recorrer às florestas como fonte de sobrevivência.

Com a ocupação, os estadosunidenses procederam com o despejo de camponeses nos domínios do Estado para estabelecer uma grande agricultura de exportação de commodities, como banana, cacau e sisal que alimentavam o mercado estadosunidense (PIERRE, 2015). Eles também restabeleceram a "corvée" - corveia - que obriga os camponeses a trabalhar de graça na construção de ferrovias. Este trabalho envolveu o corte de árvores, em média dois quilômetros de largura, ao longo das estradas construídas para o estabelecimento de propriedades agrícolas (TOUSSAINT, 2015). Como resultado, entre 1915 e 1934, nenhuma ação ou decisão foi tomada para acabar com o desmatamento que estava a serviço dos estadosunidenses. Durante esse período, o trabalho camponês foi usado para acelerar o processo de desmatamento. Em 10 de janeiro de 1933, menos de um ano após o fim da ocupação estadosunidense foi publicado um decreto que prescreve medidas para a proteção e a conservação de florestas nos domínios estatais e privados. De fato, no período da ocupação, o desmatamento não foi um problema porque serviu à economia dos estadosunidenses. Contudo, um ano antes o fim da ocupação, o desmatamento voltou a ser uma questão para o Presidente da República e o legislador haitiano. 
Neste sentido, o então Presidente haitiano, Sténio Vincent, emitiu um decreto que prescrevia medidas para a proteção e conservação das florestas (RÉPUBLIQUE D’HAÏTI, 1933), mas os estadosunidenses tiveram tempo de continuar a explorar até se aproximarem do desaparecimento de espécies como Guaiac e Tavernon (Lysiloma latisiliqua). Desde então, os camponeses são acusados de serem os novos herdeiros dos estadosunidenses no campo do desmatamento. Nesse sentido, leis, decretos e ordens foram seguidos para impedir a exploração camponesa de florestas que não servia mais à causa dos estadosunidenses. Assim, entre 1933 e 1939, uma série de seis textos governamentais sobre a questão do meio ambiente foi publicada (RÉPUBLIQUE D’HAÏTI, 1933; 1938).

Numa tentativa de remediar a situação após a ocupação, o Presidente Sténio Vincent publicou três anos após o decreto de 1933, em 04 de junho de 1936, uma lei sobre a urgência de adotar medidas adequadas para combater o desmatamento nas montanhas e planícies do território da República do Haiti, além da derrubada das árvores nas praças, ao longo das ruas e vias públicas. Essa nova lei impunha uma multa de G\$ 20 (vinte gourdes - moeda haitiana) ou prisão de vinte dias, e em caso de reincidência, uma multa de G\$50 e prisão de um mês. Outras leis, como a Lei de Regulamentação Florestal, de 24 de junho de 1937, tentaram regulamentar o corte de árvores para o comércio internacional, mas não conseguiram produzir resultados efetivos.

O então presidente Sténio Vincent publicou o decreto de 03 de maio de 1938, que institui a celebração do "Dia da Árvore", para chamar cada vez mais a atenção sobre o problema do desmatamento. Neste decreto, notou-se que a fertilidade do solo das montanhas e o sistema hidrográfico estavam ameaçados pelo desmatamento intensivo. Com efeito, era necessário lutar contra essa situação por meio de uma verdadeira campanha nacional, interessar-se tornar compreensível para todos os cidadãos, particularmente para as novas gerações, a importância das árvores na vida econômica da Nação e desenvolver o amor pela terra e respeito pela atividade agrícola. Este dia seria celebrado com cerimônias apropriadas, incluindo o plantio de árvores (RÉPUBLIQUE D’HAÏTI, 1938).

Em 1938, os camponeses carvoeiros foram identificados pelo chefe do Estado como o principal responsável pelo desmatamento. Nesse sentido, uma ordem foi emitida em 08 de outubro para proibir a exportação de carvão vegetal. Posteriormente, uma série de proibições foi tomada pelos chefes de estado da década de 1940. A primeira foi o decreto tomado pelo presidente Sténio Vincent para suspender os direitos de exportação estabelecidos sobre as toras e as raízes madeireiras.

Depois, o presidente Elie Lescot promulgou a

Lei de 01 de março de 1944, proibindo a exportação de toras e tábuas de mogno e todas as outras lenhas preciosas não manufaturadas. No ano seguinte, o mesmo presidente promulgou o Decreto-Lei de 27 de junho, mediante autorização prévia do corte, descascamento e incisão de pinheiros (Pinus), carvalho (Quercus), guaiac, bayahondes (Prosopis juliflora), campeches (Haematoxylum campechianum), cedrela (Cedrela fissilis), tavernons dentre outros.

Asism, o problema do desmatamento estava um pouco mais em voga durante o mandato do presidente Sténio Vincent, em que publicou outras leis nesse sentido. De fato, no final da Segunda Guerra Mundial, em 1945, a cobertura florestal havia diminuído para $21 \%$ e as espécies de plantas como guaiac e tavernon praticamente desapareceram. Durante a Segunda Guerra Mundial, os estadosunidenses usaram guaiac e tavernon na 
fabricação de navio de guerra (Liberty-ship) para amortecer a vibração do motor (CRESDIP, 1991).

Com a lei de 17 de agosto de 1955, que regulava o corte, transporte, comércio de lenha e forno de cal, o então presidente da República do Haiti, Paul Eugène Magloire, quis proibir o corte, descascamento ou incisão de árvores de qualquer tipo, independentemente de onde crescessem, sem autorização prévia e notificação especial por escrito de um agente qualificado do Departamento de Agricultura e sob as condições estipuladas na referida autorização, a substituição de cada árvore cortada por dez outras, tendo em conta a estação. Assim, em 1958, houve o reconhecimento da implicação do desmatamento na provocação de erosão e foi necessário tomar medidas para deter esse novo problema. Nesse sentido, a lei de 19 de setembro de 1958, foi publicada com o objetivo de proteger o solo contra erosão, determinar a extensão das zonas e regulamentar a extração madeireira no Haiti.

Na década de 1960, o Presidente François Duvalier, no que lhe concerne, dedicou um capítulo às florestas, no Código Rural de 24 de maio de 1962, no qual ficou proibido cortar, latir ou sangrar árvores sem a autorização prévia de um representante qualificado do Departamento da Agricultura, ou qualquer outro organismo competente. Posteriormente, ele publicou a lei de 05 de julho de 1966, declarando que 1966 seria o ano da abertura da campanha de reflorestamento de cinco anos em todo o país. Ações específicas foram tomadas para diminuir o desmatamento e reconstruir as florestas. Essa lei foi dirigida aos atores privados, tais como: serrarias permanentes ou móveis, empresas ferroviárias; destilarias e fábricas de açúcar e as fábricas de óleos essenciais que utilizavam largamente lenhas como energia. É uma prova de que o carvoeiro nunca foi o único ator do desmatamento.

Já o presidente Jean Claude Duvalier (Baby Doc), filho do presidente François Duvalier, seguiu as linhas de seu pai, decretando em 20 de novembro de 1972 o trabalho de reflorestamento de interesse geral e utilidade pública. Então, pelo decreto de 20 de novembro de 1972, criou uma conta não fiscal denominada: Fonds Spécial de Réflorestation - Fundo Especial de Reflorestamento - (FSR) para financiar projetos destinados à reconstituição, desenvolvimento e enriquecimento de florestas e reflorestamento de terras para combater a erosão por meio das comunidades do interior. No entanto, houve uma grande contradição na existência desta instituição, uma vez que foi financiada por compensações que foram pagos por árvore em metro cúbico para qualquer operação de corte a ser realizada nas terras do Estado e a propriedade de cidadãos particulares. Implicitamente, o Estado encorajou o desmatamento de modo a encontrar recursos para financiar a nova instituição criada.

Apesar de toda essa legislação, entre 1864 e

1950, os governos não conseguiram reverter a situação, já que a cobertura florestal estava voltada para a diminuição e o desaparecimento de certas espécies vegetais devido à exploração excessiva de florestas por cidadões haitianos e estadosunidenses. Entre 1950 e 1986, a área florestal primária do Haiti foi estimada em declínio de $18 \%$ para $03 \%$, devido ao do alto consumo de lenha (CRESDIP, 1991; FREITAS et al, 2012).

Depois de 1985, o Estado ainda não havia conseguido efetivamente limitar o desmatamento e notou o corte descontrolado de árvores que causaram condições alarmantes com a erosão das montanhas, inundações nas planícies que provocam enormes perdas de cultura e até vidas humanas. No entanto, apesar da deterioração da situação, o Estado tentou ainda remediar a situação, concedendo, por meio da Lei de 07 de julho de 1987, um prazo de 06 meses aos setores usuários de lenha, tais como: padarias, restaurantes, açucareiras e outros, para transformar o 
seu sistema de queimadores, interessar-se usar outros combustíveis. O crédito de modernização para essas novas instalações deveria ser disponibilizado para esse propósito. Após esse tempo de mudança de queimadores, os setores que não se adaptassem tiveram que ser processados de acordo com a nova lei.

As florestas haitianas foram exploradas para atender às necessidades do mercado internacional e também para cobrir o consumo nacional de energia. As leis ou decretos que estipularam medidas gerais de proteção das florestas destinavam-se principalmente a impedir a exploração das florestas em detrimento do uso nacional de madeira ou lenha convertida em energia, enquanto o estado nunca dispunha de meios para cobri-las. Apesar da promulgação de leis, o desmatamento se acelerou e cada vez mais, tendia a reduzir a cobertura florestal do país.

O desmatamento relacionado a outros problemas ambientais (erosão, inundação, deslizamento de terra) com o tempo acabou levando à decisão política de estabelecer um Ministère de l'Environnement - Ministério do Meio Ambiente (MDE) no Haiti, para lidar com esses problemas, após a publicação da Lei de 28 de março de 1995.

Observando esses problemas, o Ministère de l'Environnement (2001) argumentou que a atual situação do ambiente haitiano representava um obstáculo para o desenvolvimento do Haiti e colocava em risco o futuro de sua população, tanto por sua autossuficiência alimentar, a preservação dos ecossistemas biológicos e físicos; e sua saúde física e mental. Nessa apresentação, o Ministério observou uma situação que já estava prejudicando o processo de desenvolvimento sustentável.

\section{A SITUAÇÃO RECENTE DO DESMATAMENTO}

O desmatamento continua até hoje no Haiti, de tal forma que a cobertura florestal primária é ainda menor (D’ANS, 1987). Diante desses problemas, os produtores de carvão são acusados pelo estado haitiano como os usuários que causam a degradação ambiental, enquanto o Estado é o verdadeiro responsável para tomar medidas políticas efetivas e eficientes para acabar com esse problema (MINISTÈRE DE L'ENVIRONNEMENT, 2001). As autoridades estaduais historicamente construíram esse problema olhando as ações dos camponeses como causas da degradação ambiental, e outros setores estão aproveitando dessa situação para acusar também e construir um discurso contra os produtores de carvão. Dentre os acusadores encontram-se: o Banco Mundial, as Organizações Internacionais, as ONGs, as associações locais, etc. (LOUIS, 2008).

O desmatamento alimenta oficinas de fabricação de móveis. No entanto, está principalmente relacionado ao consumo das famílias. A maioria da população haitiana ainda usa o carvão como a única opção de energia para cozinhar alimentos, devido à falta de políticas públicas para resolver o problema do acesso à eletricidade ou gás (propano ou butano) nos domicílios. Isso mostra a irresponsabilidade do Estado, já que resolver a questão da energia é sua função.

O consumo de carvão é presente mesmo nas grandes cidades do país, principalmente, por falta de outros meios alternativos (TARTER et al, 2018). A previsão de que as reservas florestais do Haiti seriam esgotadas até o ano 2000 não é exata (VOLTAIRE, 1979). Os haitianos ainda continuam a produzir carvão, mas a produção não é mais suficiente para responder às demandas do mercado nacional. Hoje em dia, o Haiti importa carvão da República Dominicana (TARTER et al, 2018). A demanda de energia representa ao mesmo tempo, um perigo para as florestas da República vizinha. Dito de outro modo, a ineficiência das políticas públicas do estado haitiano, de cumprir as demandas energéticas da população, 
representa um desafio para o meio ambiente de toda a ilha do Haiti.

Apesar da ausência de políticas energéticas, o carvoeiro é acusado de degradação do meio ambiente, enquanto preenche apenas o vazio deixado pela irresponsabilidade do estado. A fabricação de carvão tem a pior reputação e é considerada a principal causa de degradação ambiental.

Um estudo do IHSI (2001) sobre as condições de vida dos agregados familiares, conclui que o corte de árvores é comum em agregados familiares rurais, como fonte de energia doméstica, particularmente para cozinhar. O estudo revelou qual combustível eles usavam para cozinhar e a família tinha que mencionar todos os combustíveis usados. Assim, a lenha é o combustível comumente usado para cozinhar (66\% dos domicílios) e carvão (55\% dos domicílios). O gás propano ou querosene é usado por cerca de $10 \%$ dos domicílios (INSTITUT HAÏTIEN DE STATISTIQUES ET D'INFORMATIQUE, 2001). Nas áreas rurais, a lenha é quase exclusivamente utilizada como combustível para cozinhar (92\%), enquanto nas áreas urbanas, particularmente na região metropolitana, o carvão é o mais utilizado. O gás propano e o querosene são usados quase exclusivamente em áreas urbanas (INSTITUT HAÏTIEN DE STATISTIQUES ET D'INFORMATIQUE, 2001). Poucas famílias usam gás propano e o querosene.

O uso doméstico de lenha diretamente nas residências destina-se a preencher a ausência de outras formas de energia que deveriam ser fornecidas por instituições estatais, enquanto a produção de carvão e a venda de lenha são alternativas especialmente em áreas rurais para combater a pobreza. O desmatamento não deve ser negado como uma das principais causas da degradação ambiental. No entanto, deve abordar as causas do corte de árvores (INSTITUT HAÏTIEN DE STATISTIQUES ET D'INFORMATIQUE, 2001).
Figura 2. Razões evocadas para o corte de árvore.

\begin{tabular}{|l|c|c|}
\hline RAZÃ0 EVOCADA & \% DE RESPOSTAS & \% DE CASOS \\
\hline USO DOMÉSTICO & 28 & 40 \\
\hline VENDA DE LENHA & 9 & 12 \\
\hline FABRICAÇÃO DE CARVÃ0 & 37 & 53 \\
\hline FABRICAÇÃ0 DE TÃBUA E MADEIRAS & 12 & 16 \\
\hline CONSTRUÇÃO & 10 & 14 \\
\hline OUTROS & 5 & 7 \\
\hline
\end{tabular}

Fonte: IHSI (2001) (tradução nossa).

Nesse sentido, Ilionor Louis (2008) mostra que o desmatamento é o resultado de desigualdades sociais no Haiti, em que $4 \%$ da sua população constitui uma classe dominante e que concentra $66 \%$ dos recursos do país. Há uma classe média que representa $16 \%$ da população, que atualmente está em declínio, mas possui $14 \%$ dos recursos econômicos e culturais do país, particularmente no que diz respeito à educação. $80 \%$ da população estão em pobreza ou extrema pobreza (LOUIS, 2008).

Os dados mostram que o Estado não foi capaz de cumprir a demanda em energia da população. Geralmente, as necessidades energéticas são atendidas principalmente pelos recursos locais. 55\% da energia são fornecidas diretamente por lenha, $16 \%$ por carvão derivado de lenha, $24 \%$ por combustíveis fósseis e $05 \%$ por energia hidroelétrica. As colheitas de madeira, portanto, representam $71 \%$ da energia consumida (HERARD, 2019; PROGRAMME DES NATIONS UNIES POUR L'ENVIRONNEMENT; MINISTÈRE DE L'ENVIRONNEMENT, 2010; TARTER et al, 2018). As necessidades de energia utilizadas nas cozinhas dos domicílios haitianos estão imensamente esgotadas das florestas. Ainda hoje, os haitianos continuam a atender cerca de $80 \%$ de suas necessidades energéticas para cozinhar usando lenha e produzindo carvão vegetal. No que diz respeito ao consumo de carvão, com sua população de mais 2,5 milhões de pessoas, a cidade Porto Príncipe e a sua região metropolitana são o maior consumidor desse combustível (INSTITUT HAÏTIEN DE STATISTIQUES ET D'INFORMATIQUE， 2015; TARTER et al, 2018). Assim, são cerca de 438.000 
toneladas de carvão consumidas anualmente em Porto

Príncipe (TARTER et al, 2018).

Figura 3. Origem do carvão entrando e consumindo em Porto Príncipe.

\begin{tabular}{|l|c|c|c|c|}
\hline ORIGEM & $\mathbf{1 9 7 8}$ & $\mathbf{1 9 8 5}$ & $\mathbf{1 9 9 0}$ & $\mathbf{2 0 1 7}$ \\
\hline NOROESTE & $50 \%$ & $34,2 \%$ & $21 \%$ & $1 \%$ \\
\hline ILE DE LA GONÂ̂VE & $10 \%$ & $7 \%$ & $5 \%$ & $3,4 \%$ \\
\hline ARTIBONITE & $5 \%$ & $4,8 \%$ & $13 \%$ & $9,7 \%$ \\
\hline CENTRO & N/A & $2,3 \%$ & $13 \%$ & $20,3 \%$ \\
\hline ESTE DE PORTO PRINCIPE & $5 \%$ & $5,6 \%$ & $11 \%$ & $18 \%$ \\
\hline PENÍNSULA SUL & $30 \%$ & $35,8 \%$ & $30 \%$ & $41 \%$ \\
\hline SUDESTE & N/A & $10,3 \%$ & $3 \%$ & $4,2 \%$ \\
\hline SUL (KENSCOFF/FURCY) & N/A & N/A & N/A & $0.10 \%$ \\
\hline NORTE (DEPARTAMENTO) & N/A & N/A & $4 \%$ & N/A \\
\hline REPÚBLICA DOMINICANA & N/A & N/A & N/A & $2,3 \%$ \\
\hline TOTAL & $100 \%$ & $100 \%$ & $100 \%$ & $100 \%$ \\
\hline
\end{tabular}

Fonte: Tarter et al (2018) (Tradução e adaptação nossa).

A energia elétrica deveria ser uma opção viável para substituir o consumo de carvão. Porém, a atual realidade desse setor, não está em condição de produzir energia elétrica para cumprir as necessidades dos 10,5 milhões haitianos. O cenário de energia elétrica do Haiti é controlado pela instituição estatal Électricité d'État d'Haïti - Eletricidade do Haiti (ED’H). A cobertura de eletricidade dessa instituição no país é de cerca de $38 \%$, enquanto $62 \%$ da população está sem eletricidade (RÉPUBLIQUE D'HAÏTI, 2019). A ED’H não possui condições de fornecer 12 horas de energia por dia a esses $38 \%$, uma vez que a capacidade de produção combinada das 12 redes regionais é próxima de 75 Megawatts. A ED'H também possui cerca de $1.700 \mathrm{~km}$ de linhas de transmissão e distribuição em todo o país (RÉPUBLIQUE D'HAÏTI, 2019). A ED'H não consegue apresentar uma alternativa viável para diminuir o desmatamento. $\mathrm{O}$ estado, mesmo por meio do Ministério do Meio Ambiente, afirma que a eletricidade não ajuda a fornecer soluções contra o desmatamento; muito poucas pessoas usam eletricidade para cozinhar e não há indicação de que isso vai mudar no curto prazo. Por essa razão, o setor elétrico não está incluído na estratégia energética doméstica (MINISTÈRE DE L'ENVIRONNEMENT, 2005).

O setor de produção, mesmo destruindo as florestas do Haiti, está se tornando um setor que gera rendas para muitas famílias haitianas que estão na pobreza (TARTER et al, 2018). A falta maior de fontes de energias é cada vez urgente e importante na região metropolitana de Porto Príncipe, um das principais cidades do país. Consequentemente, houve algumas organizações intergovernamentais, organizações não governamentais internacionais que se reuniram às instituições estatais e privadas haitianas para desenvolver projetos que podem cumprir as necessidades energéticas. Ariste (2018) menciona alguns projetos recentes de biogás no Haiti, implementados pelo governo haitiano ou uma combinação dessas entidades, que visam substituir o carvão. Vários projetos foram conduzidos por meio de cooperação de várias partes. Essas organizações incluem a Agência dos Estados Unidos para o Desenvolvimento Internacional (USAID), o Programa das Nações Unidas para o Meio Ambiente (PNUMA), o Fundo das Nações Unidas para a Infância (UNICEF), 
o Escritório das Nações Unidas para serviços de projetos (UNOPS) e o Viva Rio, uma ONG brasileira (ARISTE, 2018).

Enquanto soluções, como a produção de carvão vegetal alternativo a partir de resíduos agrícolas, visam resolver o problema do desmatamento no Haiti, soluções como a utilização do biogás como combustível para cozinhar, visam indivíduos que vivem nas cidades de alta densidade do Haiti. O carvão vegetal é enviado para zonas densamente povoadas, como Porto Príncipe e todas as cidades com maior concentração de pessoas. Para produzir esse carvão, o estado contou com a ajuda de várias organizações internacionais prelistadas (ARISTE, 2018). A outra experiência para substituir o carvão foi feita com combustíveis menos degradantes para o Meio Ambiente. Mas os projetos, mesmo recebendo a ajuda internacional, apresentam-se como uma opção muito cara por família. O preço dos combustíveis alternativos supera o preço da lenha e do carvão (ARISTE, 2018).

Da mesma forma, o carvão, que é tão útil quanto criticado, não deixou de interessar os legisladores, particularmente em suas relações com o desmatamento e a erosão, especialmente quando se trata de encontrar um culpado para esconder a incapacidade do estado de converter as demandas de energia da população (entrada) em medidas efetivas (saída), o que causa desequilíbrio no sistema.

\section{Figura 4. O desequilíbrio do sistema na luta contra o desmatamento}

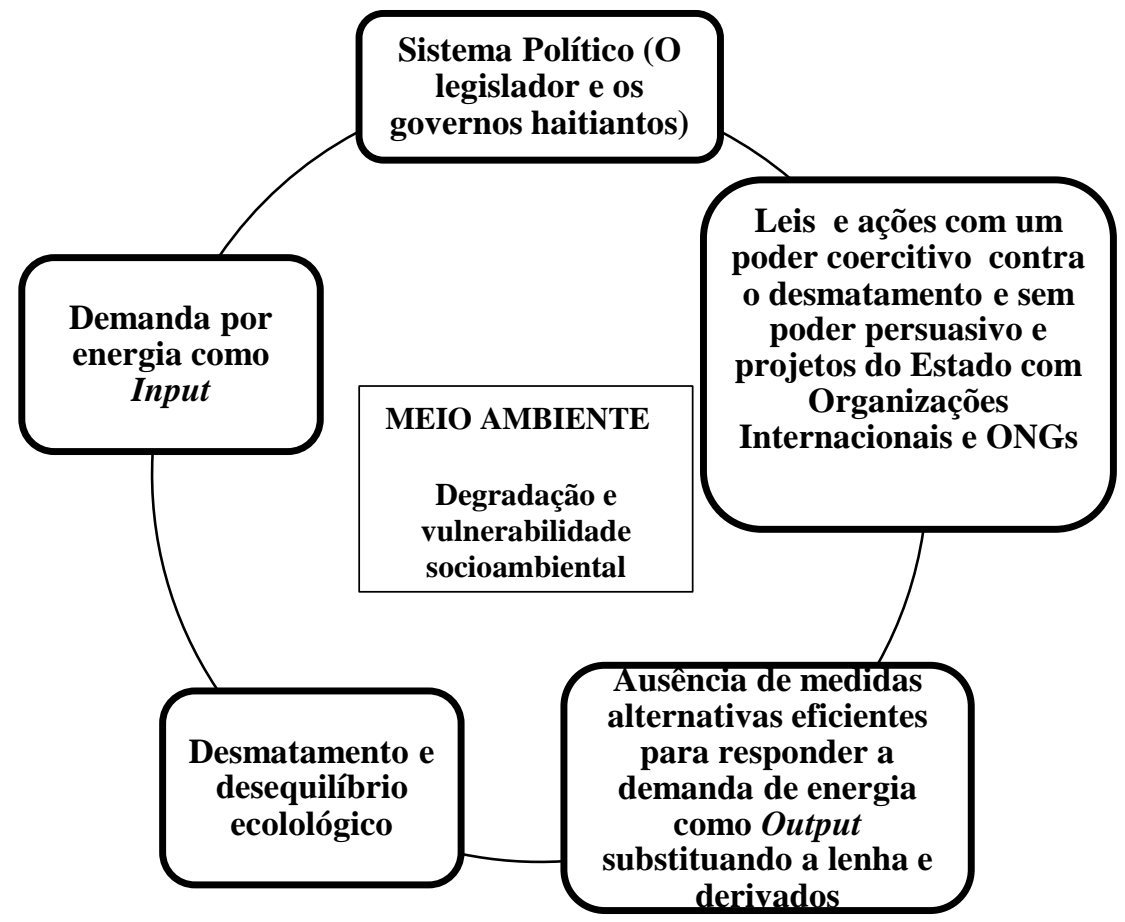

Fonte: Elaboração própria.

Outras experiências foram feitas a partir de biogás, com base na decomposição de materiais orgânicos com escassez de oxigênio. Ariste (2018) propõe uma mistura a $95 \%$, de modo a criar um gás natural para substituir o carvão.
Ainda de acordo com Ariste (2018), o gás ajudaria a reverter o desmatamento. Uma instalação capaz de converter grandes quantidades de resíduos orgânicos em biocombustível precisaria ser construída dentro da cidade que estaria fornecendo combustível 
também, mas o Estado e seus parceiros não conseguem materializar essa proposta e não há esforços suficientes para resolver esse problema. Consequentemente, o desmatamento continua sendo um dos maiores problemas a serem resolvidos pelo estado haitiano e a sua sociedade.

\section{CONCLUSÃO}

As causas da degradação da cobertura vegetal no Haiti são conhecidas por especialistas e alguns haitianos. Essas causas acabam sendo múltiplas e complexas. De fato, estão relacionadas principalmente à pobreza da maioria da população. Há muito a dizer sobre o desmatamento por meio da legislação sobre árvores e florestas. O Estado tentou criar diferentes organizações para regular o corte de árvores. No entanto, os esforços não produziram os resultados esperados. Como resultado, há muitas explicações de natureza econômica, social ou legal que colocam o sistema em desequilíbrio. Em toda a legislação sobre árvores e florestas do Haiti, o assunto é principalmente sobre proibições.

As decisões do Estado dependem do poder coercitivo, mostrando que ele está principalmente interessado em contravenções ou ofensas relacionadas ao desmatamento. Por outro lado, as decisões deste Estado negligenciam o poder persuasivo ou retributivo. Por isso, não mostra interesse suficiente em reflorestamento que represente a abordagem efetiva e positiva.

Até mesmo o Fundo Especial de Reflorestamento foi projetado para ser alimentado por impostos de corte de árvores e produção de carvão, enquanto o estado tinha que ser responsável por tomar medidas efetivas para substituir o uso de lenha e carvão por outras formas de energia, por políticas públicas energéticas. Com isso, efetivamente, a ausência de políticas públicas relacionadas à energia $\mathrm{e}$ a falta de políticas públicas ambientais eficientes criam condições nas quais a população é forçada a usar os recursos da natureza, particularmente a lenha, para satisfazer suas necessidades básicas.

\section{AGRADECIMENTO}

Agradecemos ao Programa de Alianças para Educação e a Capacitação da Organização dos Estados Americanos e o Grupo Coimbra de Universidades Brasileiras- PAEC OEA/GCUB e a Coordenação de Aperfeiçoamento de Pessoal de Nível Superior CAPES/MEC. Agradecemos também o Groupe d'Intervention pour le Développement Durable GIDD, uma organização da Sociedade civil que trabalha na promoção do Desenvolvimento sustentável no Haiti.

Todos os autores declararam não haver qualquer potencial conflito de interesses referente a este artigo.

\section{REFERÊNCIAS}

AGUILAR, L. F. Política Pública. Mexico, Siglo XXI Editores, 2010.

ARISTE, R. Biogas Program for Cooking in Haiti: Helping to Save Life, the Environment, and the Economy. Journal of Haitian Studies, v. 24 no. 1, 2018, p. 25-51. Disponível em: doi:10.1353/jhs.2018.0001. Acesso em: 28 de março de 2020 .

CADET, F. La législation haïtienne au regard de la protection de l'environnement: une analyse systémique. Dissertação. Porto-Príncipe, Université d'État d'Haiti: Faculté De Droit et des Sciences Economiques, 2006. Disponível em: https://www.memoireonline.com/10/12/6207/Lalegislation-hatienne-au-regard-de-la-protection-delenvironnement-une-analyse-systemique.html. Acesso em: 23 de junho de 2018.

CENTRE DE RECHERCHES SOCIALES ET DE DIFFUSION POPULAIRE. Haïti, terre délabrée : écologie et dictature. Porto-au-Príncipe, Imprimeur II, 1991.

COMITE

INTERMINISTERIEL D'AMENAGEMENT DU TERRITOIRE. Haïti: Objectifs et strategies territoriales pour la reconstruction. Porto-Príncipe, CIAT, 2010. Disponível em: 
http://ciat.gouv.ht/sites/default/files/docs/partie 2.pdf . Acesso em : 23 junho 2018.

D'ANS, A. M. Haïti paysage et société. Paris, Karthala, 1987.

DORVILIER, F. La crise haïtienne du développement, essai d'anthropologie dynamique. Porto Príncipe, Éditions de l'Université d'État d'Haïti, 2012.

DYE, T. R. Mapeamento dos modelos de análise de políticas públicas. In; HEIDEMANN, F. G.; SALM, J. F, (org.) Políticas Públicas e Desenvolvimento Bases Epistemológicas e modelos de análise. Brasília: Editora Universidade de Brasília, 2009.

EASTON, D. "Categorias para a análise de sistemas em política". In: EASTON, David. Modalidades de Análise Política. Rio de Janeiro, Zahar Editores, 1970, p.p 185-202.

FREITAS, C. M; CARVALHO, M. L; XIMENES, E. F; ARRAES, E. F; GOMES, J. O. Vulnerabilidade socioambiental, redução de riscos de desastres e construção da resiliência - lições do terremoto no Haiti e das chuvas fortes na Região Serrana, Brasil. Ciência \& Saúde Coletiva. Rio de Janeiro, 2012. Disponível em:

http://www.scielo.br/scielo.php?script=sci arttext\&pi $\mathrm{d}=$ S1413-81232012000600021. Acesso em: 31 de julho de 2018.

HERARD, E. Analyse des causes de la déforestation et de la dégradation forestière de la commune des Verrettes (Haïti). Dissertação de Mestrado. Université Catholique de Louvain, Louvain, 2019.

INSTITUT HAÏTIEN DE STATISTIQUES ET D'INFORMATIQUE. Enquête sur les conditions de vie en Haïti. Porto Príncipe, IHSI, 2001. Disponível em:

http://www.ihsi.ht/pdf/ecvh/pnud_livre_enquete_volu me_II.pdf. Acesso em: 02 de junho de 2018.

Projection de la population de 2018.

Port-au-Prince, Direction des Statistiques Démographiques et Sociales (DSDS), 2018.

.Population totale, population de dix-huit ans et plus. Ménages et densités estimés en 2015. Porto Príncipe: IHSI. 2015.

LOUIS, I. Haïti: Combattre le déboisement ou les inégalités sociales? Alternatives Sud, v. 15, 2008, p. 193 - 209.2 Disponível em: https://www.cetri.be/IMG/pdf/deforstationhaitipdf.pdf. Acesso em: 02 de maio de 2018.
MADIOU, T. Histoire d'Haïti (1799-1803). (LivroTome II). Porto-au-Príncipe : Éditions Henri Deschamps, 1989.

MINISTÈRE DE L'ENVIRONNEMENT. Exposé des motifs justifiant l'adoption du code de l'environnement. Porto Príncipe, MDE, 2001.

MINISTÈRE DE L'ENVIRONNEMENT. Stratégie pour l'allègement de la pression sur les ressources ligneuses nationales par la demande en combustibles. Porto Príncipe, MDE, 2005.

MOREAU DE SAINT-MÉRY, L-É. Description topographique, physique, civile, politique et historique de la partie française de l'isle SaintDomingue... (2e éd.). Paris, Édité par L. Guérin et $C^{\text {ie }}$ Théodore Morgand Librairie Dépositaire. 1875. Acesso em: gallica.bnf.fr / Bibliothèque nationale de France.

Loix et constitutions des colonies françoises de l'Amérique sous le Vent. Paris, Auteur/Imprimeur de S.A.S. Monseigneur le prince de Conti/Mesquignon jeune Librairie au Palais, à l'Écu de France, avec approbation du Roi, 1784. Acesso em: gallica.bnf.fr / Bibliothèque nationale de France.

PERCHERON, A. Les applications de l'analyse systémique à des cas particuliers. In: Revue française de sociologie, Paris, n. 12, 1971 p. 195-212. Disponível em: http://www.persee.fr/doc/rfsoc 00352969_1971_hos_12_1_1940. Acesso em: 30 de janeiro de 2020.

PIERRE, E. La paysannerie haïtienne et le secteur agricole, pendant et après l'occupation Américaine de 1915-1934 in Cent ans de domination des ÉtatsUnis d'Amérique du Nord sur Haïti. Porto-Príncipe, C3 édition, 2015.

PIERRE, Jean Abel. Sociologie Économique de la corruption. Vers une étude de l'implémentation des politiques publiques de lutte contre la corruption en Haïti. Tese doutorando em Sociologia. Université Paris Sorbonne, Paris.

POLIN, C. David Easton, ou les difficultés d'une certaine sociologie politique. In: Revue française de sociologie, Paris, n. 12, 1971, numéro spécial. Analyse de systèmes en sciences sociales (II) pp. 183-193. Disponível em: http://www.persee.fr/doc/rfsoc_00352969_1971_hos_12_1_1939. Acesso em: 26 de março de 2020.

PROGRAMME DES NATIONS UNIES POUR L'ENVIRONNEMENT; MINISTËRE DE L'ENVIRONNEMENT. État et Perspectives de l'Environnement. Porto Príncipe, GEO Haïti, 2010. 
RÉPUBLIQUE D'HAÏTI. Code-Rural d'Haïti. Le Moniteur. Porto Príncipe, n. 27 de outubro de 1864.

. Arrêté du 10 Janvier 1933 prescrivant des mesures pour la protection et la conservation des forêts tant du domaine de l'État que du domaine des particuliers. Le Moniteur, Porto-Príncipe, n. 4, 12 janeiro 1933.

. Arrêté du 3 Mai 1938 instituant le Jour de l'Arbre. Porto-Príncipe, Le Moniteur, n. 37, 9 maio 1938.

. Arrêté du 8 Octobre 1938 interdisant l'exportation du charbon de bois. Le Moniteur, PortoPríncipe, n. 14, 8 outubro 1938.

Arrêté du 9 Décembre 1933 sur l'exportation des bûches et racines de campêche. Le Moniteur, Porto-Príncipe, 9 dezembro 1933.

. Constitution de la République d'Haïti. Le Moniteur, Porto-Príncipe, n.35, 27 abril 1987.

. Décret du 20 Novembre 1972 créant un compte non fiscal dénommé: Fonds Spécial de Reboisement, (F.S.R.). Le Moniteur, Porto-Príncipe, n. 80, 27 novembro 1972.

Décret du 20 Novembrre 1972 déclarant les travaux de reboisement d'intérêt général et d'utilité publique. Le Moniteur, Porto-Príncipe, n. 80, 27 novembro 1972.

Décret-Loi du 23 Juin 1937 sur la règlementation des forêts. Le Moniteur, PortoPríncipe, no. 51, 24 junho 1937.

. Décret-loi du 27 Juin 1945 soumettant à une autorisation préalable l'abattage, l'écorçage et l'incision des pins, acajous, chênes, gaïacs, bayahondes, campêches, cèdres, tavernons, etc. Le Moniteur, Porto-Príncipe, n. 54, 5 julho 1945.

. Loi du 17 Août 1955 règlementant les cultures, la coupe et le commerce du bois et four à chaux. Le Moniteur, Porto-Príncipe, n. 87, 26 setembro 1955)
Loi du 19 septembre 1958 protégeant le sol contre l'érosion, déterminant l'étendue des zones et réglémentant l'exploitation forestière, en Haiti. Le Moniteur, Porto-Príncipe, n. 115, 13 Outubro 1958.

Loi du 1er Mars 1944 interdisant l'exportation des bûches et planches d'acajou et de tous autres bois précieux non manufacturés. Le Moniteur, Porto-Príncipe, n. 21, 13 março 1944.

Loi du 28 Mai 1936 édictant des mesures pour arrêter la déformation. Le Moniteur, Porto-Príncipe, n. 48, 4 junho 1936.

Loi du 29 Février 1904 sur l'exportation du gaiac. Le Moniteur, Porto Príncipe, n. 3 março 1904.

Loi du 5 Juillet 1966 déclarant l'année 1966 année d'ouverture de la campagne quinquennale de reboisement sur toute l'étendue du territoire. Le Moniteur, Porto-Príncipe, n.57, 14 julho 1966.

Projet de décret sur la gestion de l'environnement. Porto-Príncipe, Version soumise au Conseil des Ministres du 3 septembre 2005.

- Amélioration de l'Accès à l'Electricité en Haïti. 2019. Disponível em: http://www.ute.gouv.ht/bm/documents/SEA_FINAL_ 002.pdf. Acesso em: 07 de janeiro de 2020.

TARTER, A; FREEMAN, K. K; WARD, C; SANDER, K; THEUS, K; COELLO, B; FAWAS, Y; MILES, M; AHMED, T. T. G. Le charbon de bois en Haïti. Bilan National de la production de charbon de bois et évolution des habitudes en matière de consommation. World Bank Group, 2018.

TOUSSAINT, H. Occupation Américaine, Masses paysannes et Éducation à l'altérité in Cent ans de domination des États-Unis d'Amérique du Nord sur Haïti, Porto-Príncipe, C3 édition, 2015.

VOLTAIRE, K. Charcoal in Haiti. Report to USAID/Haiti, Porto Príncipe, 1979. 